\title{
BMJ Open Analysis of health service amenable and non-amenable mortality before and since China's expansion of health coverage in 2009
}

\author{
Xiaoqi Feng, ${ }^{1,2}$ Yunning Liu, ${ }^{3}$ Thomas Astell-Burt, ${ }^{4}$ Peng Yin, ${ }^{3}$ Andrew Page,${ }^{5}$ \\ Shiwei Liu, ${ }^{3}$ Jiangmei Liu, ${ }^{3}$ Lijun Wang, ${ }^{3}$ Maigeng Zhou ${ }^{3}$
}

To cite: Feng X, Liu Y, AstellBurt T, et al. Analysis of health service amenable and non-amenable mortality before

and since China's expansion of health coverage in 2009. BMJ Open 2016;6:e009370. doi:10.1136/bmjopen-2015009370

- Prepublication history for this paper is available online. To view these files please visit the journal online (http://dx.doi.org/10.1136/ bmjopen-2015-009370).

$\mathrm{XF}$ and $\mathrm{YL}$ are Joint first authors, each contributing equally.

Received 23 July 2015

Revised 24 November 2015 Accepted 27 November 2015

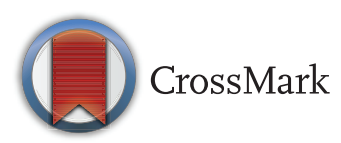

For numbered affiliations see end of article.

Correspondence to Professor Maigeng Zhou; maigengzhou@126.com

\section{ABSTRACT}

Objective: To explore early impacts of China's health reforms in 2009 on mortality.

Methods: Annual mortality counts were obtained from 161 counties across all 31 provinces of mainland China between 2006 and 2012. We examined timeseries of health service amenable mortality counts, including separate analyses for deaths from stroke and ischaemic heart diseases (IHD). Non-amenable mortality counts, including separate models for oesophageal and pancreatic cancers, were also analysed as part of a negative-outcome strategy to provide stronger foundations for falsification. Deaths due to amenable causes were hypothesised to decrease, whereas non-amenable causes of mortality would remain uninfluenced. All analyses were conducted using multilevel negative binomial regression.

Results: Geographical variation was observed for each mortality indicator, especially for IHD, oesophageal and pancreatic cancers. Negative covariances in all models indicated slight degrees of convergence in these geographic variations over time (but not significantly for deaths from oesophageal and pancreatic cancers). Linear and square functions of time indicated a curvilinear inverted parabolic trend between 2006 and 2012 for stroke and IHD mortality. Reduction in healthservice amenable mortality over time was observed, but also for health service non-amenable mortality, including deaths from oesophageal cancer. Pancreatic cancer was found to increase across the study period. In counties where residents had more years of education, mortality from stroke was lower and reducing faster over time. A similar spatiotemporal patterning was observed for deaths from oesophageal cancer, and health service amenable and non-amenable causes. Counties with higher mean education years had higher mortality from IHD and pancreatic cancer, but also larger reductions in mortality were evident in areas with greater years of education.

Conclusions: Although there was no clear evidence of an early impact of China's health reform on mortality, this does not rule out potentially important contributions to reducing the burden of disease in the longer term.
Strengths and limitations of this study

- Annual mortality time-series data from 161 locations across all 31 provinces of China.

- Multilevel random intercept-slope models to investigate spatiotemporal variation.

- Recognised classification of health service 'amenable' mortality.

- Use of 'negative outcome' technique with health service 'non-amenable' mortality.

- Data on geographic variation in health policy implementation is needed.

\section{INTRODUCTION}

Commentators suggest that a universal health insurance which provides access to good quality health services not only helps enhance health and prevents disease, ${ }^{1}$ but also serves to reduce socioeconomic inequity $^{2}$ and strengthens the workforce. ${ }^{3}$ The pursuit for universal health coverage has been reflected in developments over the past 10-15 years in China, including the landmark reforms of 2009. China's government began to re-establish rural health insurance from 2002 in which all rural Chinese residents were eligible to enrol. ${ }^{4}$ Attention then focused on cities with the launch of the urban resident basic health insurance in $2007 .^{5}$ This was followed by China's landmark reforms in 2009, which led to the rapid expansion of health insurance to over $90 \%$ of the population by the end of $2010 .{ }^{6}$ Five years on, we investigated whether the Chinese government’s investment of CN¥850 billion (US $\$ 125$ billion) had early impacts on public health.

While universal health coverage is regarded as central to social and economic policy $^{3}$ and a vital component for achieving health equity, ${ }^{7}$ the scientific evidence of 
health its impact is mixed. ${ }^{8}$ Population-wide investigations of the impact of universal health insurance are rare,$^{9}$ with most focusing either on young children ${ }^{10-13}$ or the elderly. ${ }^{14}{ }^{15}$ Previous work on the implementation of universal health coverage from 1995 onwards in Taiwan, for example, has reported a rise in health service utilisation among the newly insured ${ }^{16}$ and a marginally steeper rise in life expectancy within communities that had higher mortality rates before $1995 .{ }^{17}$ Yet both favourable and null findings have been reported on possible improvements in health status and reductions in mortality. ${ }^{18} 19$ The potential health impact of implementing universal health coverage is uncertain in a society as socially and geographically diverse as China ${ }^{20}$ Furthermore, given the proliferation of particular diseases and causes of death amenable to healthcare intervention in particular areas of China, it is unlikely that any early impacts on health have been uniform across this vast country.

Accordingly, the aim of our study was to use a nationally representative time series data (2006-2012) across mainland China spanning the period prior and subsequent to the 2009 reform to explore for early impacts of the expansion of universal coverage on public health.

\section{METHODS}

Assessments of possible change in disease incidence and associated risk factors at this present time are unlikely to yield substantial findings given that near-universal health coverage was only recently achieved in China and the lag-times on these outcomes make them more suitable to long-term follow-up. However, the influence of the exogenous expansion in health coverage may be observable within the short-term by tracking "health service amenable mortality ${ }^{21}$ before and subsequent to 2009 . The hypothesis is that the near-universal health coverage will have helped to raise standards of living, enhance health promotion and promoted greater equity of access to life-saving health services. The impact would then manifest in downward trends in mortality attributable to preventable causes, such as stroke and ischaemic heart disease (IHD).

To enhance this pre-post time-series analysis we leveraged a negative outcome study design ${ }^{22}$ wherein causes of death that could not have been affected by the health reforms were also analysed. This analysis of so-called 'negative outcomes' provides additional foundations for falsifiability of the main hypothesis that expansion of health service coverage had a favourable impact on health service amenable mortality. For this purpose, we selected oesophageal and pancreatic cancers specifically due to their short survival times, ${ }^{2324}$ as well as the broader group of mortality causes that are not classified as 'amenable'.

Access to annual mortality counts for 161 'disease surveillance points' (DSP) was provided by the Chinese Center for Disease Control and Prevention (China CDC). The DSP is nationally representative and covers a sample population of approximately 73 million people, including urban and rural counties in all 31 provinces, municipalities and autonomous regions within China. Amenable mortality (table 1) and other mortality counts were stratified by year, gender and age group (50-59 years, 6069 years, $70-79$ years, $80+$ years) at the DSP level for years 2006-2012 inclusive. Population counts from the 2010 census were used to ascertain denominators

Table 1 Amenable mortality definition

\begin{tabular}{|c|c|c|c|}
\hline No & Name & Age & ICD10 \\
\hline 1 & Intestinal infections & $0-14$ & A00-A09 \\
\hline 2 & Tuberculosis & $0-74$ & $\begin{array}{l}\text { A15-A19, } \\
\text { B90 }\end{array}$ \\
\hline 3 & $\begin{array}{l}\text { Other infectious (diphtheria, } \\
\text { tetanus, poliomyelitis) }\end{array}$ & $0-74$ & $\begin{array}{l}\text { A36, A35, } \\
\text { A80 }\end{array}$ \\
\hline 4 & Whooping cough & $0-14$ & A37 \\
\hline 5 & Septicaemia & $0-74$ & A40-A41 \\
\hline 6 & Measles & $1-14$ & B05 \\
\hline 7 & $\begin{array}{l}\text { Malignant neoplasm of colon } \\
\text { and rectum }\end{array}$ & $0-74$ & C18-C21 \\
\hline 8 & Malignant neoplasm of skin & $0-74$ & C44 \\
\hline 9 & Malignant neoplasm of breast & $0-74$ & C50 \\
\hline 10 & $\begin{array}{l}\text { Malignant neoplasm of cervix } \\
\text { uteri }\end{array}$ & $0-74$ & C53 \\
\hline 11 & $\begin{array}{l}\text { Malignant neoplasm of cervix } \\
\text { uteri and body of the uterus }\end{array}$ & $0-44$ & C54, C55 \\
\hline 12 & Malignant neoplasm of testis & $0-74$ & C62 \\
\hline 13 & Hodgkin's disease & $0-74$ & $\mathrm{C} 81$ \\
\hline 14 & Leukaemia & $0-44$ & C91-C95 \\
\hline 15 & Diseases of the thyroid & $0-74$ & E00-E07 \\
\hline 16 & Diabetes mellitus & $0-49$ & E10-E14 \\
\hline 17 & Epilepsy & $0-74$ & G40-G41 \\
\hline 18 & $\begin{array}{l}\text { Chronic rheumatic heart } \\
\text { disease }\end{array}$ & $0-74$ & $105-109$ \\
\hline 19 & Hypertensive disease & $0-74$ & $\begin{array}{l}\text { I10-I13, } \\
\text { I15 }\end{array}$ \\
\hline 20 & Ischaemic heart disease & $0-74$ & $120-125$ \\
\hline 21 & Cerebrovascular disease & $0-74$ & $160-169$ \\
\hline 22 & $\begin{array}{l}\text { All respiratory diseases } \\
\text { (excluding pneumonia/ } \\
\text { influenza) }\end{array}$ & $1-14$ & $\begin{array}{l}\text { J00-J09, } \\
\text { J20-J99 }\end{array}$ \\
\hline 23 & Influenza & $0-74$ & J10-J11 \\
\hline 24 & Pneumonia & $0-74$ & J12-J18 \\
\hline 25 & Peptic ulcer & $0-74$ & K25-K27 \\
\hline 26 & Appendicitis & $0-74$ & K35-K38 \\
\hline 27 & Abdominal hernia & $0-74$ & $\mathrm{~K} 40-\mathrm{K} 46$ \\
\hline 28 & Cholelithiasis and cholecystitis & $0-74$ & K80-K81 \\
\hline 29 & Nephritis and nephrosis & $0-74$ & $\begin{array}{l}\text { N00-N07, } \\
\text { N17-N19, } \\
\text { N25-N27 }\end{array}$ \\
\hline 30 & Benign prostatic hyperplasia & $0-74$ & N40 \\
\hline 31 & Maternal deaths & All & 000-099 \\
\hline 32 & $\begin{array}{l}\text { Congenital cardiovascular } \\
\text { anomalies }\end{array}$ & $0-74$ & Q20-Q28 \\
\hline 33 & $\begin{array}{l}\text { Perinatal deaths, all causes } \\
\text { excluding stillbirths }\end{array}$ & All & $\begin{array}{l}\text { P00-P96, } \\
\text { A33, A34 }\end{array}$ \\
\hline 34 & $\begin{array}{l}\text { Misadventures to patients } \\
\text { during surgical and medical } \\
\text { care }\end{array}$ & All & $\begin{array}{l}\text { Y60-Y69, } \\
\text { Y83-Y84 }\end{array}$ \\
\hline
\end{tabular}


Socioeconomic circumstances were measured using the mean years of education among residents within each DSP, also extracted from the 2010 census.

Descriptive analysis was conducted by calculating the mean annual mortality count for each cause of death for 2006-2012 inclusive. Statistical analysis was conducted via multilevel negative binomial regression with random coefficients to investigate potential spatiotemporal variation in each mortality count. ${ }^{25}$ An assumption of a standard random intercept multilevel model is that the relationship between and outcome and exposure is the same regardless of the higher level unit, such as a geographic area. By fitting a random coefficient between DSPs and time in our models, we allowed the relationship between mortality and time to vary between DSPs, henceforth making potential geographic deviations in mortality trends (ie, spatiotemporal variation) more observable.

Initial models were fitted with gender, age group and year as fixed effects. The year variable was fitted as in the form of linear and square terms to explore for potential curvilinear trends. This was to help account for the hierarchical data structure, wherein each DSP-level mortality count was stratified by gender, age group and year. Henceforth, level 1 within the model was the DSP-level mortality count for every combination of gender, age group and year, nested within DSPs at level 2. Linear and square functions of year were fitted into the model to assess for deviation in the mortality trends through time. The degree of potential spatiotemporal variation was assessed by observing the covariance of the random slopes. DSP-level variances were re-expressed as median rate ratios (MRR). The DSP-level mean years of education was then added to each model along with an interaction with year to explore whether there was change in the level of socioeconomic inequity over the time period. All fixed effect parameters were exponentiated to rate ratios (RR) and 95\% CIs. All analyses were conducted in MLwIN V.2.30 using penalised quasilikelihood with second order Taylor series expansion to correct for downwardly biased variances.

\section{RESULTS}

Mean health service amenable mortality was observed at $151.5 / 100000$ in 2006 , rising to $164.1 / 100000$ by 2008 , but then decreasing from 2009 onwards to 150.7/
100000 by 2012 (table 2). Stroke mortality appeared to follow a similar inverted parabolic trend, whereas IHD mortality increased across the study period. Non-amenable mortality increased from 453.7/100 000 in 2006 to $495.0 / 100000$ in 2008, falling to 487.2/ 100000 by 2012. Mortality from pancreatic cancer increased across the study period, but deaths from oesophageal cancer decreased.

Substantial geographical variation was observed for mortality counts from stroke (MRR 1.76), IHD (1.99; table 3), oesophageal cancer (2.76) and pancreatic cancer (1.95; table 4). The spatial patterning of health service amenable (1.49) and non-amenable (1.28) mortality counts was less varied by comparison (table 5 ). In models unadjusted for socioeconomic circumstances (model 1s, tables 3-5), stroke and IHD mortality increased but then curved downward over time period (table 3). Deaths from oesophageal cancer also reduced but those from pancreatic cancer increased (table 4). Both health service amenable and non-amenable causes of death appeared to decline across the study period (table 5). The covariances indicated a slight narrowing of the geographic variation of these mortality counts through the study period.

Adjusting for socioeconomic circumstances did not markedly change these results. Higher mean years of education in a DSP was associated with lower mortality from stroke, oesophageal, health service amenable and non-amenable mortality, but also higher IHD and pancreatic cancer mortality. Interaction terms indicated some degree of change in the socioeconomic patterning of each mortality outcome over time, with potential narrowing of the gradient for IHD and pancreatic cancer, but widening for other causes of death due to larger reductions in areas with greater years of education.

\section{DISCUSSION}

Unprecedented change in built, physical and socioeconomic environments associated with rapid urbanisation have manifested unevenly across China, presenting major challenges in disease prevention and detection. ${ }^{26} 27$ The expansion of health coverage in China as a result of the 2009 reforms has been interpreted an important step towards ensuring access to healthcare and protecting health in the long term. In the short

Table 2 Mortality count for each cause of death per 100000 people, by year

\begin{tabular}{lllllll}
\hline Year & Amenable & $\begin{array}{l}\text { Ischaemic } \\
\text { heart disease }\end{array}$ & Stroke & Non-amenable & $\begin{array}{l}\text { Pancreatic } \\
\text { cancer }\end{array}$ \\
\hline 2006 & 151.5 & 58.5 & 120.0 & 453.7 & 3.2 & $\begin{array}{l}\text { Oesophageal } \\
\text { cancer }\end{array}$ \\
2007 & 154.6 & 70.3 & 127.7 & 468.6 & 3.7 & 12.3 \\
2008 & 164.1 & 78.3 & 144.8 & 495.0 & 3.7 & 13.0 \\
2009 & 155.3 & 81.7 & 141.9 & 473.2 & 3.7 & 12.7 \\
2010 & 151.6 & 85.6 & 142.6 & 471.1 & 4.7 & 11.9 \\
2011 & 152.6 & 89.8 & 141.7 & 469.9 & 4.1 & 10.8 \\
2012 & 150.7 & 96.4 & 141.6 & 478.2 & & 10.7 \\
\hline
\end{tabular}


Table 3 Spatiotemporal trajectories and socioeconomic inequities in mortality from stroke and ischaemic heart disease

\begin{tabular}{|c|c|c|c|c|}
\hline & \multicolumn{2}{|l|}{ Stroke mortality } & \multicolumn{2}{|c|}{ Ischaemic heart disease mortality } \\
\hline & Model 1 & Model 2 & Model 1 & Model 2 \\
\hline Fixed part & Rate Ratio (95\% Cl) & & & \\
\hline Year & $1.08(1.04$ to 1.13$)$ & 1.09 (1.05 to 1.13$)$ & 1.10 (1.07 to 1.12$)$ & $1.10(1.07$ to 1.13$)$ \\
\hline Year $^{2}$ & 0.99 (0.98 to 0.99$)$ & 0.99 (0.98 to 0.99$)$ & 0.99 (0.99 to 0.99$)$ & 0.99 (0.99 to 0.99$)$ \\
\hline \multicolumn{5}{|l|}{ Gender (ref: male) } \\
\hline Female & 0.55 (0.54 to 0.57$)$ & 0.55 (0.54 to 0.57$)$ & 0.45 (0.43 to 0.46$)$ & $0.45(0.43$ to 0.46$)$ \\
\hline \multicolumn{5}{|c|}{ Age group (ref: 50-59 years) } \\
\hline $60-69$ & 2.92 (2.84 to 2.99$)$ & 2.92 (2.84 to 2.99$)$ & 2.58 (2.51 to 2.65$)$ & 2.58 (2.51 to 2.65$)$ \\
\hline $70-79$ & 9.77 (9.52 to 10.02$)$ & 9.77 (9.52 to 10.02$)$ & 8.28 (8.06 to 8.51$)$ & $8.28(8.06$ to 8.51$)$ \\
\hline $80+$ & 25.53 (24.89 to 26.19$)$ & 25.53 (24.89 to 26.19$)$ & 28.65 (27.87 to 29.44$)$ & 28.65 (27.87 to 29.44$)$ \\
\hline \multicolumn{5}{|c|}{ Gender×age group (years) } \\
\hline Female $\times 60-69$ & $1.10(1.06$ to 1.15$)$ & $1.10(1.06$ to 1.15$)$ & 1.37 (1.32 to 1.43$)$ & $1.37(1.32$ to 1.43$)$ \\
\hline Female $\times 70-79$ & 1.25 (1.21 to 1.30$)$ & 1.25 (1.21 to 1.30$)$ & 1.77 (1.70 to 1.84$)$ & 1.77 (1.70 to 1.84$)$ \\
\hline Female $\times 80+$ & 1.47 (1.41 to 1.52$)$ & 1.47 (1.41 to 1.52$)$ & 2.07 (1.98 to 2.15$)$ & 2.07 (1.98 to 2.15$)$ \\
\hline $\begin{array}{l}\text { Mean years of } \\
\text { education }\end{array}$ & & 0.96 (0.90 to 1.02$)$ & & 1.16 (1.08 to 1.25$)$ \\
\hline $\begin{array}{l}\text { Year×Mean years of } \\
\text { education }\end{array}$ & & 0.94 (0.91 to 0.96$)$ & & 0.97 (0.95 to 0.98$)$ \\
\hline $\begin{array}{l}\text { Year }{ }^{2} \times \text { Mean years of } \\
\text { education }\end{array}$ & & 1.01 (1.00 to 1.01$)$ & & $1.00(1.00$ to 1.01$)$ \\
\hline \multicolumn{5}{|l|}{ Random part } \\
\hline \multicolumn{5}{|l|}{ DSP $\times$ Year } \\
\hline $\begin{array}{l}\text { Intercept variance } \\
\text { (SE) [MOR] }\end{array}$ & $0.350(0.041)[1.76]$ & $0.347(0.041)$ [1.75] & $0.521(0.060)$ [1.99] & $0.485(0.056)$ [1.94] \\
\hline Covariance (SE) & $-0.094(0.015)$ & $-0.101(0.015)$ & $-0.043(0.010)$ & $-0.036(0.010)$ \\
\hline Slope variance (SE) & $0.060(0.008)$ & $0.051(0.007)$ & $0.018(0.003)$ & $0.016(0.003)$ \\
\hline \multicolumn{5}{|l|}{ DSP $\times Y_{\text {Year }}^{2}$} \\
\hline $\begin{array}{l}\text { Intercept variance } \\
\text { (SE) [MOR] }\end{array}$ & $0.010(0.002)[1.10]$ & $0.011(0.002)[1.11]$ & $0.004(0.001)$ [1.06] & $0.003(0.001)$ [1.05] \\
\hline Covariance (SE) & $-0.007(0.001)$ & $-0.006(0.001)$ & $-0.002(<0.001)$ & $-0.002(<0.001)$ \\
\hline Slope variance (SE) & $0.001(<0.001)$ & $0.001(<0.001)$ & $<0.001(<0.001)$ & $<0.001(<0.001)$ \\
\hline
\end{tabular}

term, has the expansion of health insurance in China had appreciable and early benefits or not? Building on recent work, ${ }^{28}{ }^{29}$ our study found mixed evidence for early impacts on mortality. Evidence in support of an early benefit was from the declines in mortality from health service amenable causes. The curvilinear trend of stroke and IHD mortality (rising initially then falling), is not at odds with wider literature on the nutrition transition in China ${ }^{30-32}$ but is insufficient to discount an early benefit of the health reform on its own. The concurrent upward trajectory in deaths from pancreatic cancer, which would not be expected to be influenced by the expansion of health coverage, lends support. However, declines in oesophageal cancer mortality and nonamenable causes more generally suggests that reductions in amenable mortality cannot be solely attributed to the 2009 health reform.

The provision of universal health insurance remains a fundamental determinant of health ${ }^{33}$ and the equivocal findings from our study do not rule out the likely social and economic benefits experienced in many communities across mainland China. A full appreciation of the costs and benefits will only become clearer over time and with epidemiological studies on a range of health outcomes, including time-series analyses of mortality counts. The classification of mortality into causes of death that are recognised to be health service amenable and non-amenable ${ }^{21}$ has been previously used to assess the impact of a health insurance coverage expansion in Taiwan. ${ }^{18}$ Our findings are similar in that mortality from amenable and non-amenable causes decreased during the study period. This comparison afforded a negative outcome study design, ${ }^{22}$ a method which provides stronger grounds for assessing the potential impacts of the health reform intervention. It should be noted, however, that the negative outcome approach does not necessarily provide strong evidence for or against causation. The degree of health coverage policy implementation and benefits likely varied across China but we do not have access to data with which to measure that spatiotemporal diffusion and variation in exposure. It is plausible, for example, that while the less socioeconomically well-off areas and rural communities in particular could have potentially benefitted most from the health reform, these communities may also have been less likely to receive full implementation of the policy within the 
Table 4 Spatiotemporal trajectories and socioeconomic inequities in mortality from oesophageal and pancreatic cancers

\begin{tabular}{|c|c|c|c|c|}
\hline & \multicolumn{2}{|c|}{ Oesophageal cancer mortality } & \multicolumn{2}{|c|}{ Pancreatic cancer mortality } \\
\hline & Model 1 & Model 2 & Model 1 & Model 2 \\
\hline Fixed part & Rate ratio $(95 \% \mathrm{Cl})$ & & & \\
\hline Year & $0.98(0.95$ to 1.00$)$ & 0.96 (0.93 to 0.99$)$ & 1.04 (1.01 to 1.08$)$ & $1.06(1.02$ to 1.10$)$ \\
\hline Year $^{2}$ & $1.00(0.99$ to 1.00$)$ & $1.00(0.99$ to 1.00$)$ & $1.00(0.99$ to 1.00$)$ & $0.99(0.99$ to 1.00$)$ \\
\hline \multicolumn{5}{|l|}{ Gender (ref: male) } \\
\hline Female & $0.20(0.19$ to 0.21$)$ & $0.23(0.21$ to 0.24$)$ & $0.59(0.55$ to 0.64$)$ & $0.59(0.55$ to 0.64$)$ \\
\hline \multicolumn{5}{|l|}{ Age group (ref: $50-59$ years) } \\
\hline $60-69$ & 2.38 (2.28 to 2.49$)$ & 2.44 (2.31 to 2.56$)$ & 2.26 (2.12 to 2.42$)$ & 2.27 (2.13 to 2.41$)$ \\
\hline $70-79$ & 4.67 (4.47 to 4.87$)$ & 4.84 (4.60 to 5.09$)$ & 4.59 (4.30 to 4.89$)$ & 4.56 (4.29 to 4.86$)$ \\
\hline $80+$ & 6.85 (6.52 to 7.19$)$ & $7.10(6.72$ to 7.50$)$ & 6.01 (5.55 to 6.50$)$ & 5.91 (5.48 to 6.36$)$ \\
\hline \multicolumn{5}{|l|}{ Genderxage group (years) } \\
\hline Female $\times 60-69$ & $1.42(1.31$ to 1.54$)$ & 1.39 (1.28 to 1.52$)$ & $1.14(1.02$ to 1.26$)$ & $1.13(1.02$ to 1.25$)$ \\
\hline Female×70-79 & 1.81 (1.67 to 1.95$)$ & $1.72(1.58$ to 1.88$)$ & 1.27 (1.15 to 1.41$)$ & $1.26(1.14$ to 1.39$)$ \\
\hline Female $\times 80+$ & 2.06 (1.89 to 2.24$)$ & 1.88 (1.71 to 2.06$)$ & 1.26 (1.12 to 1.42$)$ & $1.26(1.12$ to 1.40$)$ \\
\hline Mean years of education & & $0.87(0.77$ to 0.98$)$ & & $1.34(1.25$ to 1.44$)$ \\
\hline YearxMean years of education & & 0.97 (0.95 to 0.99$)$ & & $0.98(0.96$ to 1.00$)$ \\
\hline $\begin{array}{l}\text { Year }^{2} \times \text { Mean years of } \\
\text { education }\end{array}$ & & 1.00 (1.00 to 1.01$)$ & & $1.00(1.00$ to 1.01$)$ \\
\hline \multicolumn{5}{|l|}{ Random part } \\
\hline \multicolumn{5}{|l|}{ DSP $\times$ Year } \\
\hline $\begin{array}{l}\text { Intercept variance (SE) } \\
\text { [MOR] }\end{array}$ & $1.131(0.133)[2.76]$ & $1.189(0.139)[2.83]$ & $0.488(0.066)[1.95]$ & $0.343(0.049)[1.75]$ \\
\hline Covariance (SE) & $-0.024(0.017)$ & $-0.022(0.016)$ & $-0.027(0.015)$ & $-0.007(0.012)$ \\
\hline Slope variance (SE) & $0.008(0.003)$ & $0.003(0.004)$ & $0.003(0.005)$ & $0.002(0.005)$ \\
\hline
\end{tabular}

study period. Were these data to become available to empirically test, it would be possible to compare trends in mortality over time in 'treated' compared with 'untreated' communities within a regression discontinuity framework-an important and under-used study design for evaluations of the causal impact of large-scale policies on health. ${ }^{34} 35$

Previous research conducted on China's health reforms provide important context for the findings. A large repeated cross-sectional study conducted in 2003, 2008 and 2011 assessed trends in access to healthcare coverage, healthcare activities and financial protection. ${ }^{36}$ That study reported an increase in healthcare coverage from $29.7 \%$ in 2003 to $95.7 \%$ by 2011 , indicating a dramatic narrowing of inequity of access across regions and between the poorest and wealthiest. However, this was accompanied by a notable increase in hospital admissions. ${ }^{37}$ In 2011, $12.9 \%$ of households had health expenses described as 'catastrophic', with rural residents described as being particularly vulnerable. Another study, focusing on Shaanxi Province in the west of China, reported decreasing medicine prices but also reductions in the availability of the lowest-priced generic medicines in the public and private sectors between 2010 and 2012. ${ }^{38}$ This underlines our hypothesis that while healthcare insurance has achieved virtually universal coverage in China, there are other related factors such as the availability of medicines and substantial health expenses that are likely to vary geographically and, henceforth, shape spatial inequities in health outcomes. Further research with large sources of routinely collected administrative data, as well as bespoke surveys and qualitative research, are clearly required in order to fully understand the impact of health reforms in China.

Further strengths of our study include the wide geographical scope of the data spanning all 31 provinces and the analyses of disease-specific causes of mortality for comparison purposes. The latter was demonstrably important given the different levels of geographic variation and temporal trajectories in mortality. Although deaths from causes that are and are not amenable to health service intervention are typically grouped separately, an appreciation of heterogeneity within these groups is similarly crucial. It is nonetheless vital to note that DSPs can be very large and within-DSP spatial heterogeneity is unobservable with the data available and, therefore, masks changes in mortality trends at a more local scale and inequities between different population groups, such as urban migrants who do not have permanent residency status within China's megacities. ${ }^{39}$

It is important to acknowledge that the routine surveillance of mortality counts across a country as vast as China is not trivial. One key challenge is underreporting of mortality counts. Previous research ${ }^{40}$ using the DSP mortality data analysed in this study found significantly higher under-reporting of mortality in rural compared with urban areas. ${ }^{41}$ Explanations for this geographic variation in under-reporting are numerous and could potentially include less experienced medical and 
Table 5 Spatiotemporal trajectories and socioeconomic inequities in mortality from health service amenable and non-amenable causes

\begin{tabular}{|c|c|c|c|c|}
\hline & \multicolumn{2}{|c|}{ Health service amenable mortality } & \multicolumn{2}{|c|}{ Health service non-amenable mortality } \\
\hline & Model 1 & Model 2 & Model 1 & Model 2 \\
\hline Fixed part & Rate Ratio $(95 \% \mathrm{Cl})$ & & & \\
\hline Year & $0.98(0.97$ to 1.00$)$ & 0.98 (0.97 to 1.00$)$ & 0.98 (0.96 to 0.99$)$ & 0.98 (0.97 to 0.99$)$ \\
\hline Year $^{2}$ & 1.00 (1.00 to 1.00$)$ & $1.00(1.00$ to 1.00$)$ & $1.00(1.00$ to 1.00$)$ & $1.00(1.00$ to 1.00$)$ \\
\hline $\begin{array}{l}\text { Gender (ref: male) } \\
\text { female } \\
\text { Age group (ref: } 50-59 \text { years) }\end{array}$ & 0.63 (0.62 to 0.64$)$ & 0.63 (0.62 to 0.64$)$ & $0.44(0.43$ to 0.45$)$ & 0.44 (0.43 to 0.45$)$ \\
\hline 60-69 & 2.74 (2.70 to 2.78$)$ & 2.74 (2.70 to 2.78$)$ & 2.08 (2.05 to 2.12$)$ & 2.08 (2.05 to 2.12$)$ \\
\hline $70-79$ & 4.21 (4.15 to 4.28$)$ & 4.21 (4.15 to 4.28$)$ & 7.94 (7.82 to 8.07$)$ & 7.94 (7.82 to 8.07$)$ \\
\hline $\begin{array}{l}80+ \\
\text { Genderxage group (years) }\end{array}$ & 0.00 (0.00 to 0.00$)$ & 0.00 (0.00 to 0.00$)$ & 27.19 (26.77 to 27.62$)$ & 27.19 (26.77 to 27.62$)$ \\
\hline female $\times 60-69$ & $1.05(1.02$ to 1.07$)$ & 1.05 (1.02 to 1.07$)$ & $1.16(1.13$ to 1.18$)$ & $1.16(1.13$ to 1.18$)$ \\
\hline female $\times 70-79$ & 1.10 (1.07 to 1.12$)$ & 1.10 (1.07 to 1.12$)$ & 1.49 (1.46 to 1.53$)$ & 1.49 (1.46 to 1.53$)$ \\
\hline female×80+ & 0.80 (0.38 to 1.68$)$ & 0.80 (0.38 to 1.68$)$ & 1.83 (1.79 to 1.87$)$ & $1.83(1.79$ to 1.87$)$ \\
\hline Mean years of education & & 0.89 (0.86 to 0.93$)$ & & $0.92(0.90$ to 0.95$)$ \\
\hline $\begin{array}{l}\text { YearxMean years of } \\
\text { education }\end{array}$ & & 0.98 (0.97 to 0.99$)$ & & 0.99 (0.98 to 1.00$)$ \\
\hline $\begin{array}{l}\text { Year }{ }^{2} \times \text { Mean years of } \\
\text { education }\end{array}$ & & $1.00(1.00$ to 1.00$)$ & & $1.00(1.00$ to 1.00$)$ \\
\hline $\begin{array}{l}\text { Random part } \\
\text { DSP } \times \text { Year }\end{array}$ & & & & \\
\hline $\begin{array}{l}\text { Intercept variance (SE) } \\
\text { [MOR] }\end{array}$ & $0.176(0.021)[1.49]$ & $0.148(0.017)[1.44]$ & $0.068(0.008)[1.28]$ & $0.054(0.007)[1.25]$ \\
\hline Covariance (SE) & $-0.003(0.003)$ & $-0.007(0.003)$ & $-0.008(0.002)$ & $-0.009(0.002)$ \\
\hline Slope variance (SE) & $0.005(0.001)$ & $0.004(0.001)$ & $0.004(0.001)$ & $0.004(0.001)$ \\
\hline
\end{tabular}

administrative staff in rural areas, as well as lower levels of willingness among some bereaved families in rural areas to report deaths. ${ }^{42}{ }^{43}$ A study has been published comparing compared capture-mark-recapture techniques using a household survey as gold standard, based on a set of assumptions, ${ }^{44}$ with propensity score techniques to address under-reporting in China's DSP mortality data. ${ }^{40}$ The authors found the propensity score approach to correct more accurately for under-reporting and it is that adjusted data set that we have analysed in this study. It should be acknowledged, however, that death information for China's 'floating' population (eg, urban migrants without permanent residency) is incomplete and could not be analysed as a distinct group within this study.

By focusing on mortality and a relatively short study period of 7 years, including 3 years both prior and subsequent to the 2009 health reforms, other early benefits could not be assessed. These may include better geographical access to healthcare and health promotion activities that enhance community well-being, the results of which are more likely to emerge much later. A limitation of the analysis is that the DSP system, at 161 locations, did not contain information on the healthcare environments provided in each area during the time period. Our use of random coefficient multilevel models circumvented this limitation to a degree by allowing mortality trajectories for every DSP to vary over time (rather than adhere to a fixed slope for the entire country). This is an important methodological strength since, as we have already reflected on, it is unlikely that all areas of China witnessed the same level of change postreform within the short time period of this study. Further work is warranted in this regard to ascertain how much change had occurred in terms of healthcare provision at a local level.

In conclusion, mixed findings in this time-series analysis of health service amenable mortality and negative outcomes indicate that it may be too early to identify appreciable benefits of the expansion of health coverage across China. Far from refuting the position that universal healthcare is an essential social good, our study demonstrates the need for more in-depth epidemiological investigation on the potential benefits for health status, lifestyle and health service use related factors that may yet determine clear reductions in amenable mortality across China.

\section{Author affiliations}

${ }^{1}$ Early Start Research Institute, University of Wollongong, Wollongong, New South Wales, Australia

${ }^{2}$ School of Health and Society, University of Wollongong, Wollongong, New South Wales, Australia

${ }^{3}$ National Center for Noncommunicable and Chronic Disease Control and Prevention, China Center for Disease Control and Prevention, Beijing, China ${ }^{4}$ School of Science and Health, Western Sydney University, Sydney, New South Wales, Australia 
${ }^{5}$ Centre for Health Research, School of Medicine, Western Sydney University, Sydney, New South Wales, Australia

Contributors XF, TA-B and MZ conceptualised and designed the study. XF and $Y L$ conducted the statistical analyses. PY, SL, JL, LW and MZ conducted data collection, cleaning and participated data analysis. AP contributed to data interpretation. XF wrote the first and final draft of the manuscript. All co-authors contributed to the interpretation of results and redrafting of the manuscript.

Funding This study received funding from the Australian-China Science and Research Fund. XF is supported by a UIC International Links Scheme. TA-B is supported by a National Heart Foundation of Australia Postdoctoral Fellowship (\#100161)

Competing interests None declared.

Provenance and peer review Not commissioned; externally peer reviewed.

Data sharing statement No additional data are available.

Open Access This is an Open Access article distributed in accordance with the Creative Commons Attribution Non Commercial (CC BY-NC 4.0) license which permits others to distribute, remix, adapt, build upon this work noncommercially, and license their derivative works on different terms, provided the original work is properly cited and the use is non-commercial. See: http:// creativecommons.org/licenses/by-nc/4.0/

\section{REFERENCES}

1. Evans DB, Marten R, Etienne C. Universal health coverage is a development issue. Lancet 2012;380:864-5.

2. Moreno-Serra R, Smith PC. Does progress towards universal health coverage improve population health? Lancet 2012;380:917-23.

3. Frenk J, de Ferranti D. Universal health coverage: good health, good economics. Lancet 2012;380:862-4.

4. State Council and Central Committee of Communist Party of China. Decisions on further strengthening rural health development. Beijing, 2002.

5. Tang S, Tao J, Bekedam $\mathrm{H}$. Controlling cost escalation of healthcare: making universal health coverage sustainable in China. BMC Public Health 2012;12(Suppl 1):S8.

6. Yip WC-M, Hsiao WC, Chen W, et al. Early appraisal of China's huge and complex health-care reforms. Lancet 2012;379:833-42.

7. Marmot M, Friel S, Bell R, et al. Closing the gap in a generation: health equity through action on the social determinants of health. Lancet 2008;372:1661-9.

8. Levy H, Meltzer D. The impact of health insurance on health. Annu Rev Public Health 2008;29:399-409.

9. Kolstad JT, Kowalski AE. The impact of health care reform on hospital and preventive care: evidence from Massachusetts. J Public Econ 2012;96:909-29.

10. Currie J, Gruber J. Health insurance eligibility, utilization of medical care, and child health. National Bureau of Economic Research, 1995

11. Currie J, Gruber J. Saving babies: the efficacy and cost of recent expansions of Medicaid eligibility for pregnant women. National Bureau of Economic Research, 1994.

12. Hanratty MJ. Canadian national health insurance and infant health. Am Econ Rev 1996;86:276-84.

13. Chou S-Y, Grossman M, Liu J-T. The impact of national health insurance on birth outcomes: a natural experiment in Taiwan. National Bureau of Economic Research, 2011.

14. Finkelstein A. The aggregate effects of health insurance: evidence from the introduction of medicare. Q J Econ 2007;122:1-37.

15. Card D, Dobkin C, Maestas N. Does medicare save lives? National Bureau of Economic Research, 2007.

16. Shou-Hsia C, Tung-Liang $\mathrm{C}$. The effect of universal health insurance on health care utilization in Taiwan: results from a natural experiment. JAMA 1997;278:89-93.

17. Wen CP, Tsai SP, Chung W-SI. A 10-year experience with universal health insurance in Taiwan: measuring changes in health and health disparity. Ann Intern Med 2008;148:258-67.

18. Lee $\mathrm{Y}-\mathrm{C}$, Huang $\mathrm{Y}-\mathrm{T}$, Tsai $\mathrm{Y}-\mathrm{W}$, et al. The impact of universal National Health Insurance on population health: the experience of Taiwan. BMC Health Serv Res 2010;10:225.

19. Chen L, Yip W, Chang MC, et al. The effects of Taiwan's National Health Insurance on access and health status of the elderly. Health Econ 2007;16:223-42.
20. Yu SC, Tan F, Zhou MG, et al. Global burden of disease, injury and risk factor study 2010: its policy implications for China. Biomed Environ Sci 2014;27:45-8.

21. Nolte E, McKee M. Measuring the health of nations: analysis of mortality amenable to health care. BMJ 2003;327:1129.

22. Lipsitch M, Tchetgen ET, Cohen T. Negative controls: a tool for detecting confounding and bias in observational studies. Epidemiology 2010;21:383-8.

23. Conlon KC, Klimstra DS, Brennan MF. Long-term survival after curative resection for pancreatic ductal adenocarcinoma. Clinicopathologic analysis of 5-year survivors. Ann Surg 1996;223:273.

24. Dubecz A, Gall I, Solymosi N, et al. Temporal trends in long-term survival and cure rates in esophageal cancer: a SEER database analysis. J Thorac Oncol 2012;7:443-7.

25. Leyland $\mathrm{AH}$, Goldstein $\mathrm{H}$. Multilevel modelling of health statistics. Chichester, UK: Wiley, 2001.

26. Chan CK, Yao X. Air pollution in mega cities in China. Atmos Environ 2008;42:1-42.

27. Zhou M, Astell-Burt T, Bi Y, et al. Geographical variation in diabetes prevalence and detection in China: multilevel spatial analysis of 98,058 adults. Diabetes Care 2015;38:72-81.

28. Astell-Burt T, Liu Y, Feng $\mathrm{X}$, et al. Health reform and mortality in China: multilevel time-series analysis of regional and socioeconomic inequities in a sample of 73 million. Sci Rep $2015 \cdot 5 \cdot 15038-8$.

29. Zhou M, Astell-Burt T, Yin $\mathrm{P}$, et al. Spatiotemporal variation in diabetes mortality in China: multilevel evidence from 2006 and 2012 BMC Public Health 2015;15:633.

30. Adair L, Gordon-Larsen P, Du S, et al. The emergence of cardiometabolic disease risk in Chinese children and adults: consequences of changes in diet, physical activity and obesity. Obes Rev 2014;15(Suppl 1):49-59.

31. Du $\mathrm{S}$, Wang $\mathrm{H}$, Zhang $\mathrm{B}$, et al. China in the period of transition from scarcity and extensive undernutrition to emerging nutrition-related non-communicable diseases, 1949-1992. Obes Rev 2014;15(Suppl 1):8-15.

32. Zhai F, Du S, Wang Z, et al. Dynamics of the Chinese diet and the role of urbanicity, 1991-2011. Obes Rev 2014;15(Suppl 1): 16-26.

33. Commission on Social Determinants of Health. Closing the gap in a generation: health equity through action on the social determinants of health: Final Report of the Commission on Social Determinants of Health. Geneva, Switzerland: WHO, 2008.

34. Moscoe E, Bor J, Bärnighausen T. Regression discontinuity designs are underutilized in medicine, epidemiology, and public health: a review of current and best practice. J Clin Epidemiol 2015;68:122-33.

35. Bor J, Moscoe E, Bärnighausen T. Three approaches to causal inference in regression discontinuity designs. Epidemiology 2015;26: e28-30.

36. Meng $Q, X u L$, Zhang $Y$, et al. Trends in access to health services and financial protection in China between 2003 and 2011: a cross-sectional study. Lancet 2012;379:805-14.

37. Wang S, Liu L, Li L, et al. Comparison of Chinese inpatients with different types of medical insurance before and after the 2009 healthcare reform. BMC Health Serv Res 2014;14:443.

38. Fang $\mathrm{Y}$, Wagner AK, Yang S, et al. Access to affordable medicines after health reform: evidence from two cross-sectional surveys in Shaanxi Province, Western China. Lancet Glob Health 2013;1: e227-37.

39. Gusmano MK, Rodwin VG, Wang C, et al. Shanghai rising: health improvements as measured by avoidable mortality since 2000 . Int $J$ Health Policy Manag 2015;4:7-12.

40. Guo K, Yin P, Wang L, et al. Propensity score weighting for addressing under-reporting in mortality surveillance: a proof-of-concept study using the nationally representative mortality data in China. Popul Health Metr 2015;13:16.

41. Wang L, Wang LJ, Cai Y, et al. [Analysis of under-reporting of mortality surveillance from 2006 to 2008 in China]. Zhonghua $Y u$ Fang Yi Xue Za Zhi 2011;45:1061-4.

42. Hill K, Lopez AD, Shibuya K, et al. Interim measures for meeting needs for health sector data: births, deaths, and causes of death Lancet 2007;370:1726-35.

43. Rajaratnam JK, Marcus JR, Flaxman AD, et al. Neonatal, postneonatal, childhood, and under-5 mortality for 187 countries, 1970-2010: a systematic analysis of progress towards Millennium Development Goal 4. Lancet 2010;375:1988-2008.

44. Brenner $\mathrm{H}$. Use and limitations of the capture-recapture method in disease monitoring with two dependent sources. Epidemiology 1995;6:42-8. 